\title{
Brain metastases treated with hypofractionated stereotactic radiotherapy: 8 years experience after Cyberknife installation
}

Laurence Mengue ${ }^{1 *}$, Aurélie Bertaut ${ }^{2}$, Louise Ngo Mbus ${ }^{3}$, Mélanie Doré$^{4}$, Myriam Ayadi $^{1}$, Karen Clément-Colmou ${ }^{4}$, Line Claude ${ }^{1}$, Christian Carrie ${ }^{1}$, Cécile Laude ${ }^{1}$, Ronan Tanguy ${ }^{1}$, Julie Blanc ${ }^{2}$ and Marie-Pierre Sunyach ${ }^{1}$

\begin{abstract}
Background: Hypofractionated stereotactic radiotherapy (HFSRT) is indicated for large brain metastases (BM) or proximity to critical organs (brainstem, chiasm, optic nerves, hippocampus). The primary aim of this study was to assess factors influencing BM local control after HFSRT.

Then the effect of surgery plus HFSRT was compared with exclusive HFSRT on oncologic outcomes, including overall survival.

Materials and methods: Retrospective study conducted in Léon Bérard Cancer Center, included patients over 18 years-old with BM, secondary to a tumor proven by histology and treated by HFSRT alone or after surgery. Three different dose-fractionation schedules were compared: $27 \mathrm{~Gy}(3 \times 9 \mathrm{~Gy}), 30 \mathrm{~Gy}(5 \times 6 \mathrm{~Gy})$ and $35 \mathrm{~Gy}(5 \times 7 \mathrm{~Gy})$, prescribed on isodose $80 \%$. Primary endpoint were local control (LC). Secondary endpoints were overall survival (OS) and radionecrosis (RN) rate.

Results: A total of 389 patients and 400 BM with regular MRI follow-up were analyzed. There was no statistical difference between the different dose-fractionations. On multivariate analysis, surgery $(p=0.049)$ and size $(<2.5 \mathrm{~cm})$ ( $p=0.01$ ) were independent factors improving LC. The 12 months LC was $87.02 \%$ in the group Surgery plus HFSRT group vs $73.53 \%$ at 12 months in the group HFSRT. OS was $61.43 \%$ at 12 months in the group Surgery plus HFSRT group vs $50.13 \%$ at 12 months in the group HFSRT $(p<0.0085)$. Prior surgery $(O R=1.86 ; p=0.0028)$ and sex (OR $=$ $1.4 ; p=0.0139)$ control of primary tumor $(\mathrm{OR}=0.671, p=0.0069)$ and $\mathrm{KPS}<70(\mathrm{OR}=0.769, p=0.0094)$ were independently predictive of OS. The RN rate was $5 \%$ and all patients concerned were symptomatic.

Conclusions: This study suggests that HFSRT is an efficient and well-tolerated treatment. The optimal dosefractionation remains difficult to determine. Smaller size and surgery are correlated to LC. These results evidence the importance of surgery for larger BM $(>2.5 \mathrm{~cm})$ with a poorer prognosis. Multidisciplinary committees and prospective studies are necessary to validate these observations.
\end{abstract}

Keywords: Hypofractionated stereotactic radiotherapy, Brain metastases, Radionecrosis

\footnotetext{
* Correspondence: laurence2mengue@gmail.com

'Department of Radiotherapy, Léon Bérard Cancer Center, Lyon, France

Full list of author information is available at the end of the article
}

(c) The Author(s). 2020 Open Access This article is licensed under a Creative Commons Attribution 4.0 International License, which permits use, sharing, adaptation, distribution and reproduction in any medium or format, as long as you give appropriate credit to the original author(s) and the source, provide a link to the Creative Commons licence, and indicate if changes were made. The images or other third party material in this article are included in the article's Creative Commons licence, unless indicated otherwise in a credit line to the material. If material is not included in the article's Creative Commons licence and your intended use is not permitted by statutory regulation or exceeds the permitted use, you will need to obtain permission directly from the copyright holder. To view a copy of this licence, visit http://creativecommons.org/licenses/by/4.0/ The Creative Commons Public Domain Dedication waiver (http://creativecommons.org/publicdomain/zero/1.0/) applies to the data made available in this article, unless otherwise stated in a credit line to the data. 


\section{Background}

Brain metastases (BM) occur in up to $20-40 \%$ of all cancer patients [1]. Their incidence increases with the development of performant imaging and the advances of systemic therapies providing a longer survival [2]. Neurologic symptoms associated to BM can significantly impact quality of life [3]. Local treatment arsenal for BM includes neurosurgery, whole brain radiotherapy (WBRT), stereotactic radiosurgery (SRS) and more recently hypofractionated stereotactic radiotherapy (HFSRT) [4]. SRS is largely reported in literature. The use of SRS is however correlated to a high risk of radionecrosis [5]. Large lesions distant from critical structures are preferably treated by surgery [6]. In case of surgical contraindication HFSRT may be an option [7]. HFSRT provides radiobiological advantages compared to SRS when BM are larger or closer to critical structures such as brainstem or chiasm $[8,9]$. HFSRT offers the ability to deliver higher dose in terms of radiobiological equivalent dose on large $\mathrm{BM}$, and to reduce toxicity of normal brain tissue [9]. HFSRT probably improves the therapeutic ratio and increases tumor control probability as suggested by an in silico study [8]. However, one of HFSRT relevant challenges is to assess the optimal dose and fractionation regimen associated to local control of BM, according to size and volume [9].

The objectives of this study were to investigate prognostic factors influencing BM local control (LC), overall survival (OS) and radionecrosis (RN) development, in patients treated by HFSRT in the clinical practice of a single institution over 8 years. Thus, the effect of surgery plus HFSRT was compared with exclusive HFSRT on oncologic outcomes, including overall survival.

\section{Materials and methods}

\section{Study population}

This is a retrospective and monocentric study conducted at the Léon Bérard Cancer Center in Lyon. Eligible patients were over 18 years of age, treated by exclusive intracranial HFSRT or surgery with post-operative HFSRT. All patients had a histological proof of primary tumor by biopsy. Patients who underwent prior WBRT or surgery were also included in outcome analysis. Exclusion criteria were the presence of primary intracranial tumors (e.g. meningioma or glioblastoma), and other stereotactic irradiation. This study was ethically approved by the Léon Bérard Cancer Center institutional board.

\section{Data collection}

The main clinical data were extracted from computerized patients' records were: age, sex, Karnofsky performance status (KPS), primary tumor histology, extracranial disease control. Prognostic scores Recursive Partitioning Analysis (RPA) [10], modified Recursive Partitioning Analysis (mRPA) [11, 12], Graded Prognostic Assessment (GPA)
[13], Diagnostic-Specific Graded Prognostic Assessment (DS-GPA) were calculated for each patient [13] . Neurological symptoms prior BM treatment (motor or sensitive dysfunction, intracranial hypertension, and aphasia) were also reported from retrospective data [3]. The assessment of neurological symptoms was only qualitative. We also took into account the systemic treatments delivered concomitantly or within 1 month of radiotherapy, as well as whether or not the extracerebral disease was controlled. The systemic treatments included chemotherapy, targeted therapy and immune-checkpoint inhibitors [14] .The fact that the extracerebral disease is not controlled may be related either to a bifocal recurrence or to an initial metastatic tumour.

Regarding BM characteristics, reported informations were maximal diameter, number and location. BM diagnosis was performed either on a cerebral MRI, biopsy or operative piece histology. Percentage of meningial spreading was also assessed for brain metastases treated by surgery and HFSRT [15] .

\section{Hypofractionated stereotactic radiotherapy (HFSRT)}

For each patient, surgery or HFSRT indication was discussed at a multidisciplinary staff meeting. HFSRT was delivered by Cyberknife ${ }^{\mathrm{Tm}}$ (Accuray Inc., Sunnyvale, CA). The non-injected simulation CT-scanner was performed in supine position.

A thermoformed frame mask system was used. MRI images ( $1 \mathrm{~mm}$ slice thickness) were registered with planning CT scan (1 mm slice thickness) on Multiplan (Accuray) workstation. Gross Tumor Volume (GTV) corresponded to contrast-enhancing lesion on $\mathrm{T} 1$ sequences of brain fusion MRI. If an adjuvant HFSRT was performed, GTV represented the surgical cavity. In both cases, a $2 \mathrm{~mm}$ margin was systematically added to GTV to generate the planning target volume (PTV). When $\mathrm{BM}$ was closer to critical structures, margin could be reduced to $0-1 \mathrm{~mm}$ and organs at risk (OAR) was excluded from PTV.

The main risk-delineated organs were brainstem, optic nerves, chiasm and hippocampus. Dose and fractionation regimens were chosen at the discretion of the radiotherapist, depending on the BM size, OAR proximity (brainstem, corpus callosum, optic nerves and chiasm), and prior WBRT or surgery. For the smaller lesions, 3 fraction protocols are frequently used. Concerning larger lesions or lesions located near OAR or in functional sites, 5 fraction schedules are used. The prescription isodose was $80 \%$. Treatment plan validation was done according to PTV coverage (up to 95\%) and respect of maximal dose received by OAR according Timmerman recommendations [16].

Brain metastases or post-operative cavities were irradiated on alternate day, every other day. 
Follow-up after HFSRT

The follow-up was based on a clinical neurological examination and on a brain MRI every 3 months 1 st year and every 6 months the following years, according to ANOCEF recommendations [17].

\section{Study endpoints}

Primary endpoint was local control defined by stability, partial or complete response of the lesion after HFSRT. Secondary endpoints were overall survival (OS) and rate of radionecrosis (RN). OS corresponded to the interval between the date of HFSRT and date of last follow-up or death. The definition of RN was more extensive and heterogeneous. The RN diagnosis was performed on MRI surveillance or histology [18] . Further images as spectrometric MRI could be requested, if there was uncertainty between RN or local failure diagnosis $[19,20]$. MRI were reviewed by an experimented radiotherapist. Stability of $\mathrm{BM}$ size over several months was in favor of $\mathrm{RN}$.

\section{Statistical analysis}

Categorical variables were presented as numbers (percentage) and continuous variables were described as median and standard deviation (minimum and maximum values).

LC and RN analyses were performed using a per-lesion basis. Evaluation of OS was conducted on per-patient basis. Kaplan Meier curves were generated to estimate both endpoints. Log-Rank test was used to assess predictive factors on survival outcomes.

For OS and LC estimates, living patients were censored at the last follow-up and for others, at the most recent visit or death.

Cox univariate and multivariate regression were performed to determine independent predictive factors of local control and OS. Co-variables with $p$-value less than 0.2 on univariate analysis, were introduced in the statistical model. Variables with more than $20 \%$ missing data were not included in the multivariate model. All tests were two sided and $P$ values were considered significant when less than 0.05. Analyzes were performed using the SAS 9.4 statistical software.

\section{Results}

\section{Patient population}

Between January 2011 and January 2018, a total of 427 patients were treated by HFSRT at Léon Bérard Cancer Center. Median age was 62 years-old (18-87). There were 188 men and 239 women. WBRT was performed before HFSRT on 39 patients (9\%).

Patients characteristics are presented in Table 1. Patients were divided into two groups Surgery plus HFSRT and HFSRT. Both groups were similar in terms of age, sex, GPA, DS-GPA, systemic treatment and control of
Table 1 Characteristics of patients

\begin{tabular}{|c|c|c|c|}
\hline & $\begin{array}{l}\text { Surgery + HFSRT } \\
\boldsymbol{N}=99\end{array}$ & $\begin{array}{l}\text { HFSRT } \\
\boldsymbol{N}=328\end{array}$ & pValue \\
\hline Age & & & 0.1511 \\
\hline Median [min - max] & 59.0 [13.2-87.0] & 60.8 [8.3-85.9] & \\
\hline Sex & & & 0.4587 \\
\hline male & $52(52.5 \%)$ & $185(56.7 \%)$ & \\
\hline Female & $47(47.5 \%)$ & $143(43.3 \%)$ & \\
\hline KPS & & & 0.25 \\
\hline $100-90$ & $38(38 \%)$ & $96(30 \%)$ & \\
\hline $80-70$ & $46(46 \%)$ & $169(52 \%)$ & \\
\hline$<70$ & $15(15 \%)$ & $60(18 \%)$ & \\
\hline RPA & & & $<.0001$ \\
\hline 1 & $29(29.3 \%)$ & $35(10.7 \%)$ & \\
\hline 2 & $55(55.6 \%)$ & $233(71.0 \%)$ & \\
\hline 3 & 15 (15.2\%) & $60(18.3 \%)$ & \\
\hline m RPA & & & $<0.001$ \\
\hline $1+2 a$ & $55(56 \%)$ & $89(27 \%)$ & \\
\hline $2 b$ & $17(17 \%)$ & $90(28 \%)$ & \\
\hline $2 c+3$ & $27(27 \%)$ & $146(45 \%)$ & \\
\hline GPA & & & 0.0868 \\
\hline$<=3$ & 98 (99.0\%) & $311(94.8 \%)$ & \\
\hline$>3$ & $1(1.0 \%)$ & 17 (5.2\%) & \\
\hline DS-GPA & & & 0.2485 \\
\hline$<=3$ & 78 (87.6\%) & $265(91.7 \%)$ & \\
\hline$>3$ & $11(12.4 \%)$ & $24(8.3 \%)$ & \\
\hline Not applicable & 10 & 39 & \\
\hline $\begin{array}{l}\text { Survival at the } \\
\text { last follow-up }\end{array}$ & & & 0.0227 \\
\hline Alive & $63(63.6 \%)$ & $166(50.6 \%)$ & \\
\hline Dead & $36(36.4 \%)$ & $162(49.4 \%)$ & \\
\hline Extracranial control & & & 0.0001 \\
\hline Yes & $49(49.5 \%)$ & $116(34.4 \%)$ & \\
\hline No & 41 (41.4\%) & $182(55.5 \%)$ & \\
\hline NC & $9(9.1 \%)$ & $30(9.1 \%)$ & \\
\hline Neurologic symptoms & & & $<.0001$ \\
\hline No & 77 (77.8\%) & $133(52.0 \%)$ & \\
\hline Yes & $22(22.2 \%)$ & $123(48.0 \%)$ & \\
\hline NC & 0 & 72 & \\
\hline Systemic treatement & & & 0.3197 \\
\hline No & $56(58.3 \%)$ & $197(64.0 \%)$ & \\
\hline Yes & $40(41.7 \%)$ & $111(36.0 \%)$ & \\
\hline Control of primary tumor & & & 0.6333 \\
\hline Yes & 49 (50.5\%) & $148(47.7 \%)$ & \\
\hline No & 50 (49.5\%) & 180 (52.3\%) & \\
\hline
\end{tabular}


primary tumor. Significant differences between both groups were based on extracranial control, neurologic symptoms, RPA and mRPA.

\section{Brain metastasis}

A total of 535 BM was identified in the study and 400 BM (389 patients) were followed with an MRI. Median size was $2.3 \mathrm{~cm}(0.6-6.5 \mathrm{~cm})$. The main histology and location was lung cancer (55\%), followed breast cancer (12\%), clear cell renal carcinoma (10\%) and melanoma (5.2\%). On 535 BM, 88 (20\%) had surgical resection before HFSRT. Among BM treated by surgery and HFSRT, 13 cases of meningial spreading were detected on MRI or cytology. BM were split into radio resistant group (clear cell carcinoma cancer, sarcoma and melanoma) and radiosensitive group (other histological types), counting 120 and $414 \mathrm{BM}$ respectively.

In the group of Surgery plus HFSRT (Table 2), 71\% BM were larger than $2.5 \mathrm{~cm}$ vs $36.7 \%$ in comparison with the group HFSRT $(p<.0001)$. More than half of post-

Table 2 Characteristic of treated brain metastasis

\begin{tabular}{|c|c|c|c|}
\hline & $\begin{array}{l}\text { Surgery + HFSRT } \\
\boldsymbol{N}=105\end{array}$ & $\begin{array}{l}\text { HFSRT } \\
\boldsymbol{N}=429\end{array}$ & pvalue \\
\hline Size & & & $<.0001$ \\
\hline$<2.5 \mathrm{~cm}$ & 29 (29.0\%) & 246 (63.2\%) & \\
\hline $2.5-4 \mathrm{~cm}$ & 47 (47.0\%) & $123(31.6 \%)$ & \\
\hline \multirow[t]{2}{*}{$>4 \mathrm{~cm}$} & 24 (24.0\%) & 20 (5.1\%) & \\
\hline & 5 & 40 & \\
\hline $\begin{array}{l}\text { Total dose and } \\
\text { fractionation (gy) }\end{array}$ & & & $<.0001$ \\
\hline 27 & 12 (11.4\%) & $202(47.1 \%)$ & \\
\hline 30 & 54 (51.4\%) & 108 (25.2\%) & \\
\hline 35 & 39 (37.1\%) & 119 (27.7\%) & \\
\hline WBRT & & & 0.0329 \\
\hline Yes & $3(2.9 \%)$ & $35(8.1 \%)$ & \\
\hline No & $102(97.1 \%)$ & 394 (91.9\%) & \\
\hline Tumor Histology & & & 0.5626 \\
\hline Breast & $13(12.4 \%)$ & 53 (12.4\%) & \\
\hline Kidney & 7 (6.7\%) & 40 (9.3\%) & \\
\hline Lung & 64 (61.0\%) & $231(53.8 \%)$ & \\
\hline Melanoma & $3(2.9 \%)$ & 25 (5.8\%) & \\
\hline Other & $18(17.1 \%)$ & 80 (18.6\%) & \\
\hline Location & & & 0.0614 \\
\hline Brainstem & $0(0.0 \%)$ & $15(3.5 \%)$ & \\
\hline Infratentorial & 32 (30.5\%) & $100(23.3 \%)$ & \\
\hline Supratentorial & 73 (69.5\%) & 314 (73.2\%) & \\
\hline radiosensible & & & 0.4984 \\
\hline Yes & 84 (80.0\%) & 330 (76.9\%) & \\
\hline No & 21 (20.0\%) & 99 (23.1\%) & \\
\hline
\end{tabular}

operative cavities received a dose of $30 \mathrm{~Gy}$ in 5 fraction or 35 in 5 fractions. In the group HFSRT, a dose of 27 Gy in 3 fractions was applied on $47.1 \%(n=202)$. Concerning prior systemic treatment, there was no significant differences between both groups (Table 1).

\section{Local control}

Analyses were performed on $400 \mathrm{BM}$ with available follow-up images. Patients excluded from analyses of LC because of inadequate imaging follow up were not statistically different from patients included in analyses. The median follow-up is 40 months (1-60 months). If we consider the whole group, local control at 6 months, 1year and 2 -years was $88 \%, 76.5$ and $63.9 \%$ respectively. In the group of patients treated with Surgery +HFSRT, the local control was $89.58 \%$ at 6 months, $87.02 \%$ at 12 months $77.53 \%$ at 24 months vs $88.17 \%$ at 6 months, $73.75 \%$ at 12 months, $59.93 \%$ at 24 months in the groupe of patients treated with exclusive HFSRT (Fig. 1). LC was improved when size was less than to $2.5 \mathrm{~cm}(p=$ 0.0164) (Fig. 2). On univariate analyses and multivariate, maximal $\mathrm{BM}$ size $(<2.5 \mathrm{~cm})$ and prior surgery were the only predictive factor of LC (Table 4). Systemic treatment and fractionation schedules were not statically associated with LC (Table 4).

For further analyses, BM were divided into 4 groups of treatment modality. The group of patients treated by surgery plus adjuvant HFSRT was compared to 3 other groups of BM treated by $3 \times 9 \mathrm{~Gy}, 5 \times 6 \mathrm{~Gy}$, and $5 \times 7 \mathrm{~Gy}$ schedules (Fig. 3). Surgery had a significant impact on LC $(p=0.0469)$, whereas dose-fraction regimen had no impact (Table 3).

\section{Overall survival}

With a median follow-up of 40 months (1-60 months) median overall survival was 13.17 months (10.68-17.22). One-year OS was $52.7 \%$. Overall survival at 12 months was $61.43 \%$ in the surgery +HFSRT group vs $50.13 \%$ in the HFSRT group $(p<0.0085)$ (Fig. 4).

On Cox univariate model, clinical parameters such as sex, RPA, mRPA, GPA, DS-GPA, control of extra cerebral tumor, prior surgery and KPS were significantly associated with overall survival, whereas age, DS-GPA, radio sensitivity were not (Table 4). In Cox Multivariate model, prior surgery $(\mathrm{OR}=1.86 ; p=0.0028)$, $\operatorname{sex}(\mathrm{OR}=$ 1.4; $p=0.0139)$, control of extra cerebral tumor $(\mathrm{OR}=$ $0.671, p=0.0069)$ and $\mathrm{KPS}<70(\mathrm{OR}=0.769, p=0.0094)$ were independently predictive for OS (Table 4).

\section{Late toxicity: radionecrosis}

With a median follow-up of 16.4 months (5.6-71.8 months), a total of 20 cases (5\%) of RN were reported above $400 \mathrm{BM}$ with regular MRI follow-up. All patients presented neurologic symptoms. For RN diagnosis, followup MRI was mandatory (at least 2 consecutive MRI with 


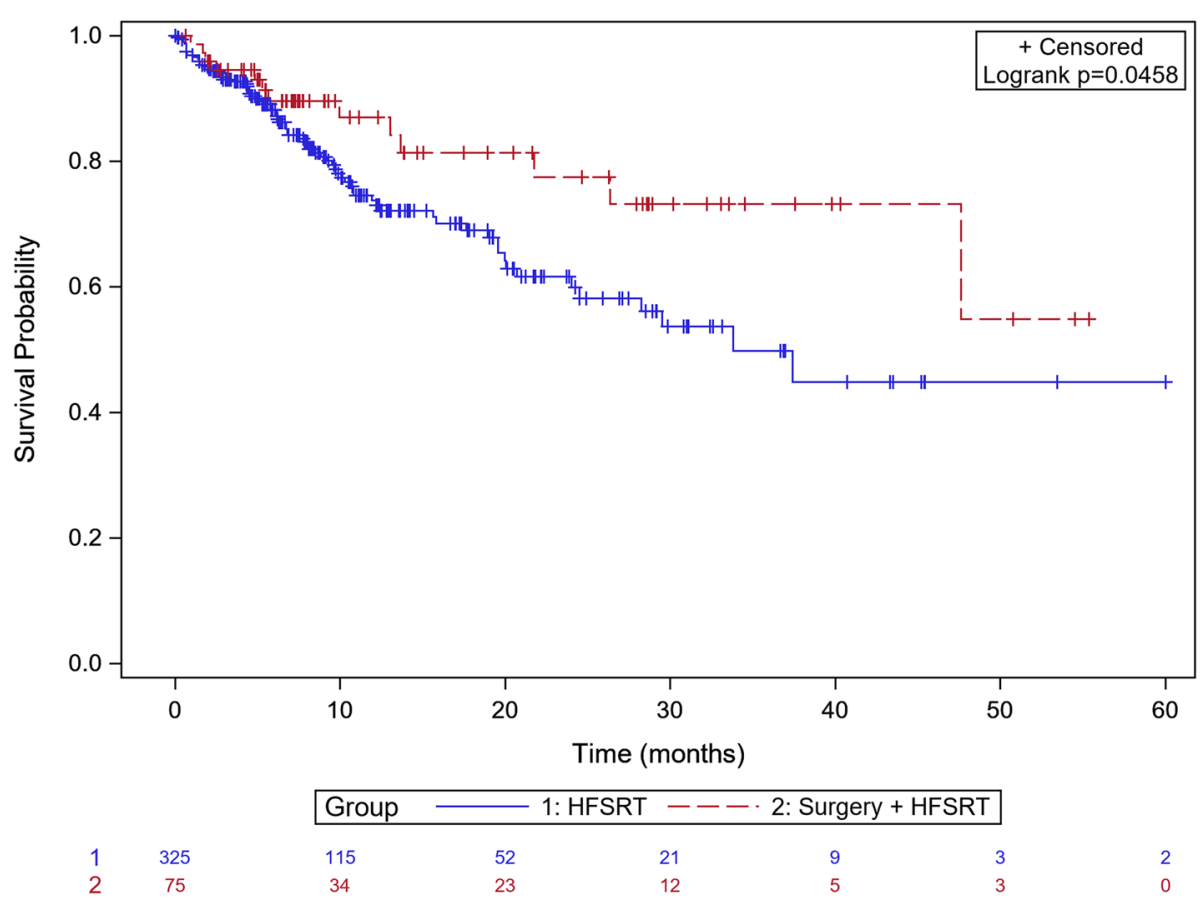

Fig. 1 Kaplan Meier curve of local control

RN diagnosis). Follow-up MRI performed were multimodal with T1, T2, FLAIR and perfusion sequences. Most of RN occurred on BM originated from lung cancer $(n=$ $10 ; 50 \%)$, followed by breast cancer $(n=6 ; 30 \%)$, melanoma $(n=2 ; 10 \%)$, digestive tract $(n=1 ; 5 \%)$, head and neck cancer $(n=1 ; 5 \%)$. Median size of BM was $2.3 \mathrm{~cm}(1-4 \mathrm{~cm})$.
RN occurred on 7 post-operative cavities (35\%). Two patients needed surgery because of neurologic symptoms.

\section{Discussion}

This study aimed to assess the efficiency and safety of HFSRT with or without surgery. In our institution,

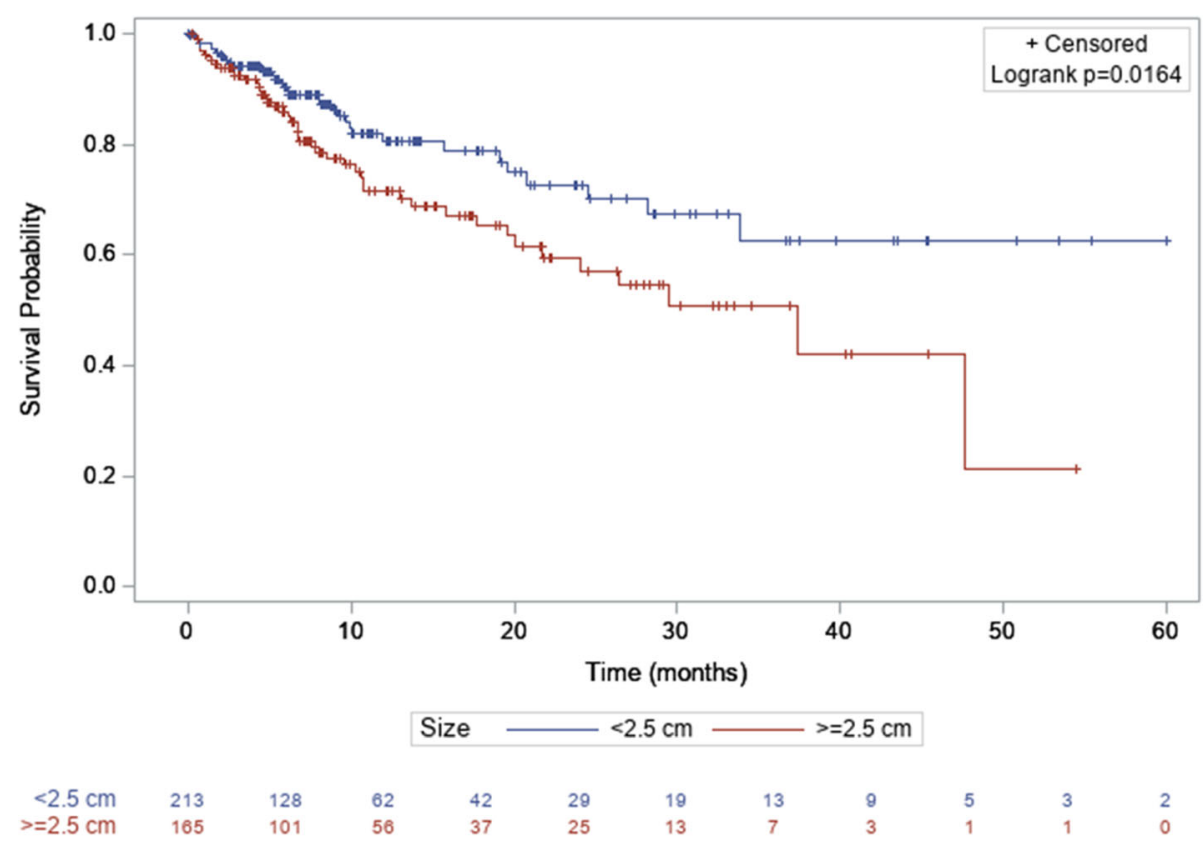

Fig. 2 Kaplan Meier curve of local control in function brain metastases size 


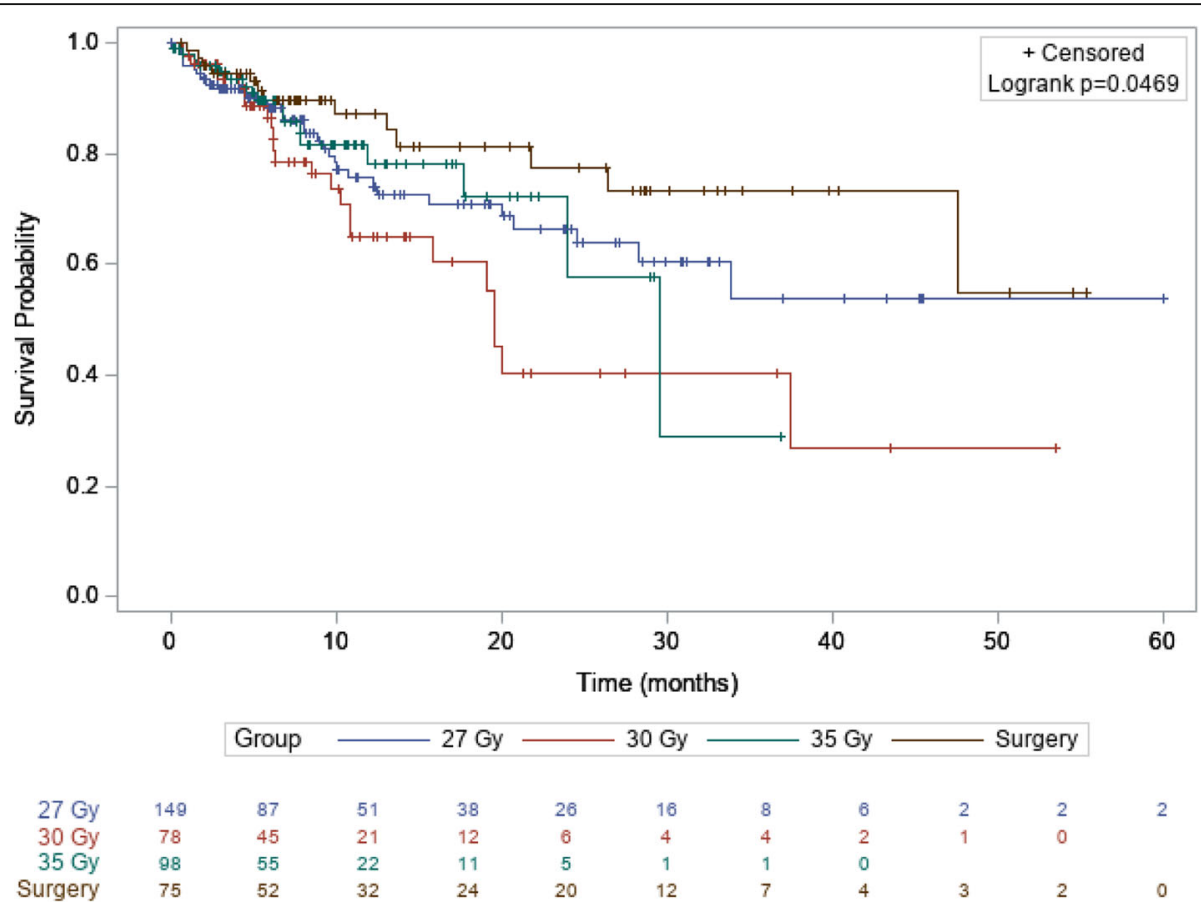

Fig. 3 Kaplan Meier curve of local control according to surgery and dose-fraction regimens. The group surgery represents all patients treated by surgery followed by HFSRT (27, 30 or 35 Gy)

HFSRT and SRS were used upfront WBRT, even if multiple BM were observed $(>3)$ to reduce late neurocognitive toxicity. This practice was supported by EORTC study comparing WBRT vs surveillance after surgery or SRS [21]. Their data demonstrated that median overall survival was not significantly different between both groups (10.7 months vs 10.9 months; $p=0.89$ ). More recently a second analysis was performed and showed similar results: Churilla et al. compared limited BM 1 to 3 vs extended BM (>
3) and concluded that number of BM treated by SRS was not associated to overall outcome [22].

Patients with multiple BM were more likely to have extracranial progression. Therefore, we found an estimated overall 1 year survival of $52.7 \%$, which is lower than what it was found in some studies [23] previously reported previous studies.

For each patient RPA, mRPA, GPA, and DS-GPA prognostic scores were calculated and reported. On

Table 3 Univariate and multivariate analyses on local control (LC)

\begin{tabular}{|c|c|c|c|c|c|c|c|}
\hline \multicolumn{5}{|l|}{ Univariate analyses } & \multicolumn{3}{|c|}{ Multivariate analyses } \\
\hline Variable & $\mathrm{N}$ & $H R$ & IC95\% & $\mathrm{p}$ & $H R$ & IC95\% & $\mathrm{p}$ \\
\hline Size & $N=378$ & & & 0.0178 & & & 0,0072 \\
\hline$>=2.5 \mathrm{~cm}$ vs $<2.5 \mathrm{~cm}$ & & 1.699 & {$[1.096-2.634]$} & & 1.909 & [1.191-3.060] & \\
\hline Fractionation & $N=400$ & & & 0.3902 & & & 0,2072 \\
\hline 30 Gy in 5 vs 27 Gy in 3 & & 1.331 & [0.823-2.151] & & 0.917 & [0.508-1.655] & \\
\hline 35 Gy in 5 vs 27 Gy in 3 & & 0.955 & {$[0.553-1.649]$} & & 1.453 & [0.853-2.477] & \\
\hline Control of primary tumor & $N=383$ & & & 0.0598 & & & \\
\hline Yes vs No & & 0.661 & {$[0.429-1.017]$} & & & & \\
\hline Systemic treatment & $N=382$ & & & 0.9556 & & & \\
\hline Yes vs No & & 0.987 & {$[0.630-1.546]$} & & & & \\
\hline Surgery & $N=400$ & & & 0.0490 & & & 0,0044 \\
\hline Yes vs no & & 1.816 & {$[1.002-3.289]$} & & 2.506 & {$[1.333-4.712]$} & \\
\hline Group & $N=400$ & & & 0.0490 & & & \\
\hline Surgery + HFSRT vs HFSRT & & 0.551 & [0.304-0.998] & & 0.437 & [0.235-0.812] & 0,0088 \\
\hline
\end{tabular}




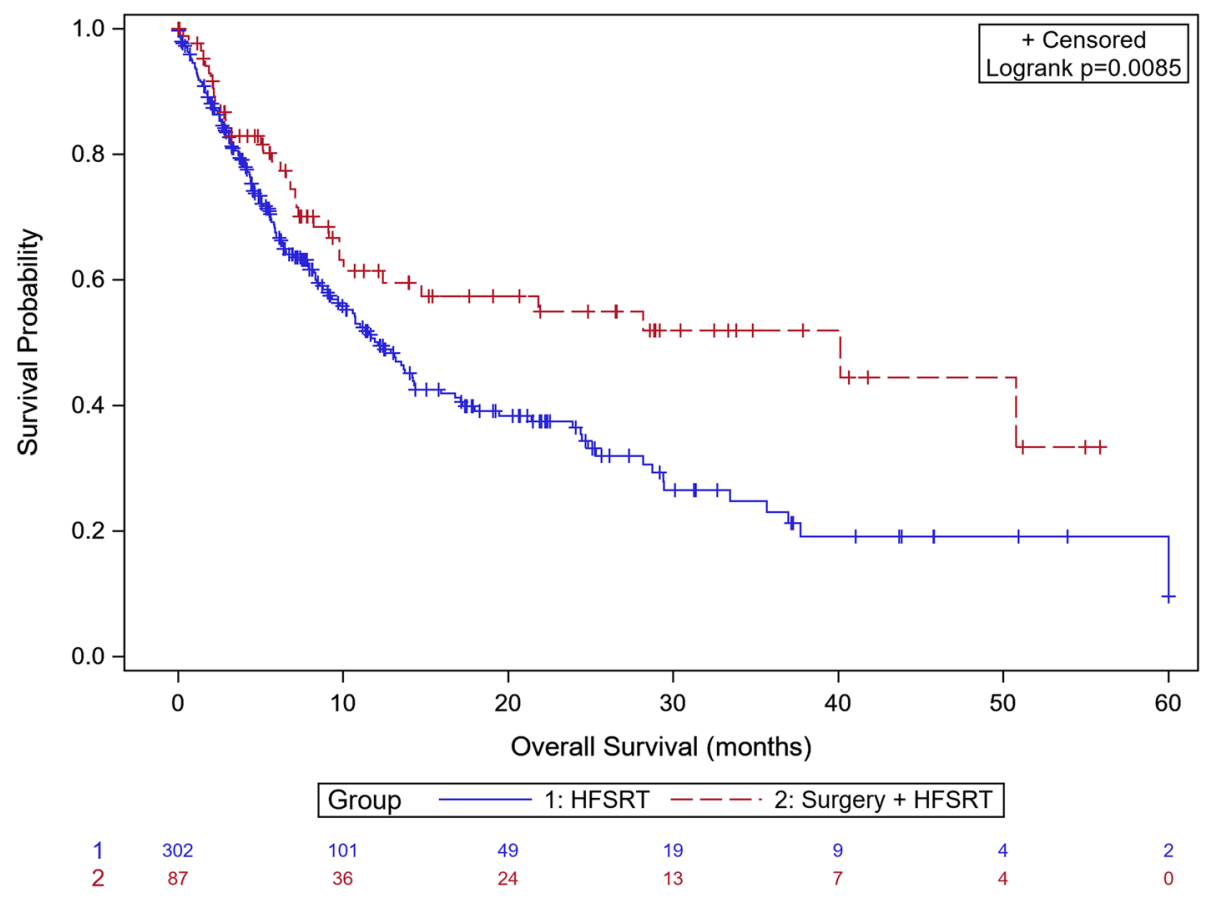

Fig. 4 Kaplan Meier curve of overall survival according to surgery

univariate analyses, RPA mRPA and GPA were significantly associated with overall survival. On multivariate analysis, only mRPA was significantly associated to overall survival. According literature, mRPA is more discriminant than RPA [11]. The group 2 from RPA score is heterogenous [12]. Thus, many studies suggested that a subclassification of group 2 is necessary to predict more accurately overall survival [12]. Our finding might be in agreement with those observations.

However our study might be limited by the fact that nomograms were not systematically used before HFSRT indication. Moreover, even if these scores systems have been validated, they were developed based on patients treated by WBRT and not by SRS or HFSRT alone [13, 24]. Each score refers to different predictive factors such as age, BM number, histology of primitive tumor and performance status score [22, 25]. Nieder et al. suggested that all these criteria can not be reported in some clinical situations [26]. Other publications showed that $\mathrm{cu}-$ mulated volume size and surgery should be integrated in nomogram [7, 27]. Therefore, it is impossible to take into account all those factors highlighting the importance of a multidisciplinary staff meeting.

In the present series local control was $88,76.5$ and $63.9 \%$ at 6 months, 1 year and 2 years, respectively. This is in agreement with literature showing that HFSRT is an efficient treatment for BM (Table 5). Those studies are mainly retrospective and included small cohorts. However, their data reported a satisfying local control at 1 year (76 and
93\%). The only prospective study based on HFSRT included 51 patients and local control was $76 \%$ at 1 year [28].

Our study analyzed dose-fractionation prescribed on the same isodose (80\%). Intent was to adapt fractionation regimen to clinical situations. Higher dosefractionation $5 \times 7$ Gy corresponded to a biological equivalent dose with $\alpha / \beta=10$ (BED10 Gy) of $59.9 \mathrm{~Gy}$, was delivered on larger BM $(>2.5 \mathrm{~cm})$. Schedules $3 \times 9$ Gy and $5 \times 6$ Gy corresponding to lower BED10 Gy of 51.3 Gy and 48 Gy respectively, were more often applied on post-operative cavity and smaller lesions [29]. In Table 2, we can see that physician's adapted volume fractionation, number of lesions prior to WBRT or surgery. In regard of literature, rare studies assessed the indication of HFSRT for smaller BM $(<2.5 \mathrm{~cm})$ $[29,30]$. Studies that analyzed HFSRT outcomes were mainly focused on larger BM [7]. In our study, we also included smaller BM treated by HFSRT at the proximity of eloquent structure. Although, dose and fractionation schedule prescriptions were influenced by clinical parameters, none of the HFSRT fractionation schedules emerged as an optimal treatment leading to a significantly improvement of local control no matter BM size.

In our study BM size was the main prognosis factor influencing local control. Local control was better when BM were smaller $<2.5 \mathrm{~cm}$. Our results are consistent with literature showing that size is a robust prognosis factor of local control upon SRS and HFSRT [8, 27]. 
Table 4 Univariate and multivariate analysis on OS

\begin{tabular}{|c|c|c|c|c|c|c|c|}
\hline \multirow[b]{2}{*}{ Variable } & \multirow[b]{2}{*}{$\mathrm{N}$} & \multicolumn{3}{|c|}{ Univariate analyses } & \multicolumn{3}{|c|}{ Multvariate analyses } \\
\hline & & $\mathrm{HR}$ & IC95\% & $p$ & $\mathrm{HR}$ & IC95\% & $p$ \\
\hline Age & $N=389$ & & & 0.0891 & & & 0.4633 \\
\hline$<70$ vs $\geq 70$ & & 1.402 & [0.69-1.525] & & 1.473 & [0.574-1.353] & \\
\hline Sex & $N=387$ & & & 0.0024 & & & 0.0139 \\
\hline Female vs Male & & 1.578 & [1.175-2.12] & & 1.578 & [1.08-2.00] & \\
\hline KPS & $N=389$ & & & 0.0094 & & & 0.0094 \\
\hline$v<70$ vs $\geq 70$ & & 0.622 & {$[0.435-0.89]$} & & 0.769 & [0.522-1.133] & \\
\hline RPA & $N=389$ & & & 0.0301 & & & 0.4 \\
\hline II-III vs I & & 1.756 & [1.08-2.854] & & 0.799 & {$[0.472 ; 1.35]$} & \\
\hline m RPA & $N=389$ & 1.700 & & 0.001 & 1.74 & [1.12-2.69] & 0.014 \\
\hline II-III vs I & & & {$[1.1-2.854]$} & & & & \\
\hline GPA & $N=389$ & & & 0.0342 & & & 0.1411 \\
\hline$<3$ vs $\geq 3$ & & 0.642 & [0.427-0.968] & & 0.712 & {$[0.45-1.12]$} & \\
\hline DS-GPA & $N=345$ & & & 0.3525 & & & \\
\hline$<3$ vs $\geq 3$ & & 0.842 & [0.587-1.209] & & & & \\
\hline Surgery & $N=389$ & & & 0.00111 & & & 0.0028 \\
\hline Yes vs No & & 1.623 & [1.117-2.357] & & 1.86 & [1.24-2.79] & \\
\hline Symptoms & $N=322$ & & & 0.696 & & & \\
\hline No vs Yes & & 0.956 & [0.697-1.312] & & & & \\
\hline Single BM & $N=389$ & & & 0.696 & & & \\
\hline Yes vs No & & 1.074 & [0.752-1533] & & & & \\
\hline Radiosensitivity & $N=389$ & & & 0.2592 & & & \\
\hline Yes vs No & & 0.83 & [0.601-1.147] & & & & \\
\hline Control of primary tumor & $N=373$ & & & 0.0036 & & & 0,0087 \\
\hline Yes vs No & & 0.645 & {$[0.480-0.867]$} & & 0.671 & {$[0.497-0.904]$} & \\
\hline Systemic treatment & $N=370$ & & & 0.6987 & & & \\
\hline Yes vs No & & 0.942 & {$[0.694-1.277]$} & & & & \\
\hline Group & $N=389$ & & & 0.0092 & & & 0,0089 \\
\hline Surgery + HFSRT vs HFSRT & & 0.601 & [0.419-0.884] & & 0.410 & [0.419-0.884] & \\
\hline
\end{tabular}

However, definition of large BM is heterogeneous among studies, making the comparison difficult [6].

Our data demonstrated that larger BM $(>2.5 \mathrm{~cm})$ had worse local control whatever the dose and fractionation. In Léon Bérard Cancer Center, a dose escalation was performed up to $35 \mathrm{~Gy}$ on larger tumors. Despite this dose escalation, this suggests that larger BM still have poorer local control compared to smaller lesions. Adaptation of fractionation to tumor volume failed to compensate the bad prognostic induced by tumor volume. Some authors suggested the use of a further fractionated treatment. Determining optimal dose is a controversial debate [31]. Partly this can be explained by fundamental radiobiology [29]. The larger the $\mathrm{BM}$ is, the more important the hypoxic fraction is, leading to radioresistance [30]. Another explanation may be that dosefractionation used in brain cannot reach higher BED10
Gy due to dose constraints [16]. In extracranial stereotactic body radiotherapy, it is well established that dose escalation is strongly linked to cell death and tumor decrease when BED10 Gy is higher [23, 32, 33].

Late toxicity (radio necrosis) was limited to $5 \%$ in this large cohort. All patients with diagnosed radionecrosis were symptomatic. Radionecrosis diagnosis was performed on MRI follow-up most of the time. Minitti and al. performed analyses on a large cohort including 289 patients [34]. A group treated by SRS was compared to a group treated by HFSRT. Nineteen percent of patients in the SRS group vs $9 \%$ in the HFSRT group presented a radionecrosis. In our study this rate was lower. The incidence of radionecrosis depends on the definition. Asymptomatic RN are not reported in this study. Nonetheless, Zindler et al. demonstrated that HFSRT reduces $R N$ rate [8] . Indeed, the higher the fraction 
Table 5 Literature review of hypofractionated stereotactic studies

\begin{tabular}{|c|c|c|c|c|c|c|c|c|c|}
\hline $\begin{array}{l}\text { Publication } \\
\text { date }\end{array}$ & $\begin{array}{l}\mathrm{Nb} \\
\mathrm{pts} / \\
\mathrm{BM}\end{array}$ & $\begin{array}{l}\text { Median Volume }(\mathrm{cc}) \text { or size } \\
(\mathrm{mm})\end{array}$ & Regimen & $\begin{array}{l}\text { Isodose } \\
\text { (\%) }\end{array}$ & $\begin{array}{l}\text { WBRT } \\
(\%)\end{array}$ & $\begin{array}{l}\text { LC at } 12 \mathrm{~m} \\
(\%)\end{array}$ & $\begin{array}{l}\text { Median } \\
\text { OS } \\
\text { at } 12 \mathrm{~m} \\
(\%)\end{array}$ & $\begin{array}{l}\mathrm{RN} \\
(\%)\end{array}$ & $\begin{array}{l}\text { Prognostic } \\
\text { factors }\end{array}$ \\
\hline $\begin{array}{l}\text { Matsuyama et al. 2005- } \\
2009\end{array}$ & $\begin{array}{l}299 / \\
573\end{array}$ & $8.6 \mathrm{~mm}(2.8-47.4)$ & $\begin{array}{l}\text { Variable } \\
\text { regimen }\end{array}$ & $\mathrm{NC}$ & 10 & 94 & 57,8 & 2 & Size \\
\hline $\begin{array}{l}\text { Lliang-hua et al. 2001- } \\
2011\end{array}$ & $\begin{array}{l}171 / \\
354\end{array}$ & $14.3 \mathrm{cc}(0.16-86)$ & $4 \times 8$ Gy & $80-90$ & 68 & 68 & 51 & 6 & WBRT for OS \\
\hline $\begin{array}{l}\text { Martens et al. 2006- } \\
2010\end{array}$ & $\begin{array}{l}75 / \\
108\end{array}$ & 1 cc (0.1-29.2) & $\begin{array}{l}6 \mathrm{Gyx5} \\
6-7 \times 5 \mathrm{gy} \\
7-10 \times 4 \text { Gy }\end{array}$ & NC & 52 & 52 & 35 & 1 & Volume \\
\hline $\begin{array}{l}\text { Giubilei et al. 2001- } \\
2006\end{array}$ & $30 / 44$ & $4.8 \subset c(0.4-24.3)$ & $\begin{array}{l}3 \times 6 \mathrm{~Gy} \\
4 \times 8 \mathrm{~Gy}\end{array}$ & Isocenter & 100 & 86 & 36 & 0 & NC \\
\hline $\begin{array}{l}\text { Marchetti et al. 2001- } \\
2005\end{array}$ & $65 / 81$ & $8 \subset c(0.3-48.2)$ & $3 \times 8$ Gy & 80 & 44 & 58 & 25 & 1 & NC \\
\hline Fahrig et al. 2000-2005 & $\begin{array}{l}150 / \\
228\end{array}$ & $30 \mathrm{~mm}$ & $\begin{array}{l}5 \times 6-7 G y \\
10 x 4 G y \\
7 \times 5 G y\end{array}$ & $\mathrm{NC}$ & 34 & $\mathrm{NC}$ & 66 & NC & Dose volume \\
\hline Jiang et al. 2003-2009 & $40 / \mathrm{NC}$ & $\begin{array}{l}30 \mathrm{~mm}(3.1-5.5) \\
17,5 \mathrm{cc}(6-64.6)\end{array}$ & $4 \times 10$ gy & 90 & 25 & 94.2 & 55.3 & 2.5 & Histology KPS \\
\hline $\begin{array}{l}\text { Scorsettiet al. 2004- } \\
2007\end{array}$ & $\begin{array}{l}78 / \\
113\end{array}$ & 3.3 cc (0.1-28) & $\begin{array}{l}6 \times 4 G y \\
7 \times 5 G y \\
1 \times 20 \mathrm{~Gy}\end{array}$ & 80 & 10 & 69 & NC & NC & RPA \\
\hline Nagai et al. 2009-2013 & $\begin{array}{l}54 / \\
128\end{array}$ & 1.9 cc (0.1-18) & $4 \times 7$ Gy & 80 & NC & 91 & 52 & 0 & NC \\
\hline Fokas et al. 2012 & $\begin{array}{l}214 / \\
214\end{array}$ & $30 \mathrm{~mm}$ & $\begin{array}{l}7 \times 5 \text { Gy } \\
4 \times 10 G y\end{array}$ & Isocenter & 0 & 90 & 31 & NC & RPA \\
\hline Ernst et al. 2003-2005 & $51 / 72$ & $3 c c$ & $\begin{array}{l}5 \times 7 \text { Gy } \\
5 \times 6 \text { Gy }\end{array}$ & NC & NC & NC & NC & NC & $V 4<20 c c$ \\
\hline Inoue et al. 2010-2014 & $88 / 92$ & $10-74 c c$ & $\begin{array}{l}3 \times 9 \mathrm{~Gy} \\
3 \times 10 \mathrm{~Gy}\end{array}$ & 57 & 0 & 90 & NC & 0 & $\begin{array}{l}\text { V14 } \\
\text { RN }\end{array}$ \\
\hline
\end{tabular}

LC local control, V14 Irradiated volume receiving $14 \mathrm{~Gy}, R N$ Radionecrosis, RPA Recursive Patitioning Analysis, $m$ months, Vol Volume, $N C$ not communicated, pts. patients, $N b$ Number

number, the more OAR are protected from late toxicity. A 24 studies meta-analyse conducted by lerhar et al. also demonstrated that HFSRT offers lower rate of radio-necrosis with an improved LC [35].

Surgery is a prognostic factor correlated to local control and overall survival on multivariate analysis. This finding suggests that surgery should be proposed for BM larger than $2.5 \mathrm{~cm}$, when this feasible without morbidity. Previous studies compared post-operative SRS versus SRS alone. Local control after surgery alone is estimated to $50 \%$ [4]. A recent prospective phase III study compared follow-up or SRS after surgery [36]. The local free recurrence at 1 -year was $43 \%$ in the group treated by surgery vs $72 \%$ the group treated by surgery plus SRS. Lamba et al. found that surgery plus SRS was associated with an improved LC and overall survival in comparison to SRS alone [37].

To our knowledge, this is one of largest studies comparing HFSRT and surgery plus HFSRT. In the EORTC study comparing SRS or surgery with or without WBRT, including 289 patients, local control and global survival were comparable between both groups. This suggested that SRS is as efficient as surgery. For patients not eligible to surgery due to multiple or deep BM, optimal dose-fractionation should be assessed by randomized prospective studies. Association with systemic agents should be further investigated [38-40].

\section{Conclusion}

Our study suggests that HFSRT is an efficient and safe treatment. Lesion size and surgery are correlated to a robust local control. Surgery may provide a better outcome in term of overall survival. This study confirms the importance of surgery in BM management. Further studies are required to assess the interest of dose escalation in BM management.

\section{Abbreviations}

ANOCEF: Association des Neuro-Oncologues d'Expression Française; BED10 Gy: Biological equivalent dose with $\alpha / \beta=10$; BM: Brain metastases; DSGPA: Diagnostic-Specific Graded Prognostic Assessment; GPA: Graded Prognostic Assessment; GTV: Gross Tumor Volume; HFSRT: Hypofractionated stereotactic radiotherapy; KPS: Karnofsky performance status; LC: Local control; OAR: Organs at risk; OS: Overall survival; PTV: Planning target volume; RN: Radionecrosis; RPA: Recursive Partitioning Analysis; SRS: Stereotactic radiosurgery; WBRT: Whole brain radiotherapy 


\section{Acknowledgements}

We thank Isabel Gregoire, PhD Medical Writer CGFL, and Gilles Créhange for carefully reading the manuscript.

\section{Authors' contributions}

The study was carried out by Laurence Mengue and was supervised by Marie-Pierre SUNYACH. All authors reviewed the manuscript before submission. The author(s) read and approved the final manuscript.

\section{Funding}

No funding to declare.

\section{Availability of data and materials}

Datasets generated for this study are available upon request to the corresponding author.

\section{Ethics approval and consent to participate}

This study was ethically approved by the Léon Bérard Cancer Center institutional board.

\section{Consent for publication}

Not applicable.

\section{Competing interests}

The authors declare that they have no competing interests.

\section{Author details}

'Department of Radiotherapy, Léon Bérard Cancer Center, Lyon, France. ${ }^{2}$ Methodology and Biostatistics Unit, Centre Georges François Leclerc, Dijon, France. ${ }^{3}$ Department of Medecine, Hôpital d'Aurillac, Aurillac, France. ${ }^{4}$ Department of Radiation Oncology, Institut de Cancérologie de l'Ouest, Nantes, France.

\section{Received: 12 November 2019 Accepted: 19 March 2020} Published online: 17 April 2020

\section{References}

1. Fox BD, Cheung VJ, Patel AJ, Suki D, Rao G. Epidemiology of metastatic brain tumors. Neurosurg Clin N Am janv. 2011;22(1):1-6 v.

2. Soffietti R, Abacioglu U, Baumert B, Combs SE, Kinhult S, Kros JM, et al. Diagnosis and treatment of brain metastases from solid tumors: guidelines from the European Association of Neuro-Oncology (EANO). Neuro-Oncol. 2017;19(2):162-74.

3. Noh T, Walbert T. Brain metastasis: clinical manifestations, symptom management, and palliative care. Handb Clin Neurol. 2018;149:75-88.

4. Arvold ND, Lee EQ, Mehta MP, Margolin K, Alexander BM, Lin NU, et al. Updates in the management of brain metastases. Neuro-Oncol. 2016;18(8): 1043-65.

5. Andrews DW, Scott CB, Sperduto PW, Flanders AE, Gaspar LE, Schell MC, et al. Whole brain radiation therapy with or without stereotactic radiosurgery boost for patients with one to three brain metastases: phase III results of the RTOG 9508 randomised trial. Lancet. 2004;363(9422):1665-72.

6. Masucci GL. Hypofractionated radiation therapy for large brain metastases. Front Oncol. 2018:8:379.

7. Ahmed KA, Sarangkasiri S, Chinnaiyan P, Sahebjam S, Yu H-HM, Etame AB, et al. Outcomes following Hypofractionated stereotactic radiotherapy in the Management of Brain Metastases. Am J Clin Oncol. 2016;39(4):379-83.

8. Zindler JD. Improving patient selection and outcome of stereotactic radiosurgery as a single treatment modality for brain metastases. 2017; University of Maastricht; Disponible sur: https://doi.org/10.26481/dis. $20171025 j \mathrm{j}$.

9. Kumar AMS, Miller J, Hoffer SA, Mansur DB, Coffey M, Lo SS, et al. Postoperative hypofractionated stereotactic brain radiation (HSRT) for resected brain metastases: improved local control with higher BED10. J Neurooncol. 2018;139(2):449-54.

10. Gaspar L, Scott C, Rotman M, Asbell S, Phillips T, Wasserman T, et al. Recursive partitioning analysis (RPA) of prognostic factors in three radiation therapy oncology group (RTOG) brain metastases trials. Int J Radiat Oncol. 1997;37(4):745-51.
11. Yamamoto M, Kawabe T, Higuchi Y, Sato Y, Nariai T, Watanabe S, et al. Validity of prognostic grading indices for brain metastasis patients undergoing repeat radiosurgery. World Neurosurg. 2014;82(6):1242-9.

12. Yamamoto $M$, Sato $Y$, Serizawa $T$, Kawabe $T$, Higuchi $Y$, Nagano $O$, et al Subclassification of recursive partitioning analysis Class II patients with brain metastases treated radiosurgically. Int J Radiat Oncol Biol Phys. 2012;83(5): 1399-405.

13. Sperduto PW, Kased N, Roberge D, Xu Z, Shanley R, Luo X, et al. Summary report on the graded prognostic assessment: an accurate and facile diagnosis-specific tool to estimate survival for patients with brain metastases. J Clin Oncol. 2012;30(4):419-25.

14. Chamberlain MC, Baik CS, Gadi VK, Bhatia S, Chow LQM. Systemic therapy of brain metastases: non-small cell lung cancer, breast cancer, and melanoma. Neuro-Oncol. 2017;19(1):i1-24.

15. Atalar B, Modlin LA, Choi CYH, Adler JR, Gibbs IC, Chang SD, et al. Risk of Leptomeningeal disease in patients treated with stereotactic radiosurgery targeting the postoperative resection cavity for brain metastases. Int J Radiat Oncol. 2013;87(4):713-8.

16. Timmerman R, Bastasch M, Saha D, Abdulrahman R, Hittson W, Story M. Stereotactic body radiation therapy: Normal tissue and tumor control effects with large dose per fraction. IMRT IGRT SBRT. 2011:43:382-94.

17. Le Rhun É, Dhermain F, Noël G, Reyns N, Carpentier A, Mandonnet E, et al. ANOCEF guidelines for the management of brain metastases. Cancer Radiother J Soc Francaise Radiother Oncol. 2015;19(1):66-71.

18. Minniti G, Esposito V, Clarke E, Scaringi C, Bozzao A, Falco T, et al. Fractionated stereotactic radiosurgery for patients with skull base metastases from systemic cancer involving the anterior visual pathway. Radiat Oncol. 2014;9(1):110.

19. Le Rhun E, Dhermain F, Vogin G, Reyns N, Metellus P. Radionecrosis after stereotactic radiotherapy for brain metastases. Expert Rev Neurother. 2016; 16(8):903-14.

20. Minniti G, Clarke E, Lanzetta G, Osti M, Trasimeni G, Bozzao A, et al. Stereotactic radiosurgery for brain metastases: analysis of outcome and risk of brain radionecrosis. Radiat Oncol. 2011;6(1):48.

21. Kocher M, Soffietti R, Abacioglu U, Villà S, Fauchon F, Baumert BG, et al. Adjuvant whole-brain radiotherapy versus observation after radiosurgery or surgical resection of one to three cerebral metastases: Results of the EORTC 22952-26001 Study. J Clin Oncol. 2011;29(2):134-41.

22. Churilla TM, Handorf E, Collette S, Collette L, Dong Y, Aizer AA, et al. Whole brain radiotherapy after stereotactic radiosurgery or surgical resection among patients with one to three brain metastases and favorable prognoses: a secondary analysis of EORTC 22952-26001. Ann Oncol Off J Eur Soc Med Oncol. 2017:28(10):2588-94.

23. Fahrig A, Ganslandt O, Lambrecht U, Grabenbauer G, Kleinert G, Sauer R, et al. Hypofractionated stereotactic radiotherapy for brain metastases. Strahlenther Onkol. 2007;183(11):625-30

24. Sperduto PW, Wang M, Robins HI, Schell MC, Werner-Wasik M, Komaki R, et al. A phase 3 trial of whole brain radiation therapy and stereotactic radiosurgery alone versus WBRT and SRS with Temozolomide or Erlotinib for non-small cell lung Cancer and 1 to 3 brain metastases: radiation therapy oncology group 0320. Int J Radiat Oncol. 2013;85(5):1312-8.

25. Nieder C. What approach will Lead to cure of Glioblastoma Multiforme?: in regard to Barani et al. (Int J Radiat Oncol biol Phys 2007;68:324-333) and Jones and Sanghera (Int J Radiat Oncol biol Phys 2007:68:441-448). Int J Radiat Oncol. 2007;69(2):640-1.

26. Nieder C, Marienhagen K, Geinitz H, Molls M. Validation of the graded prognostic assessment index for patients with brain metastases. Acta Oncol. 2009:48(3):457-9.

27. Baschnagel AM, Meyer KD, Chen PY, Krauss DJ, Olson RE, Pieper DR, et al. Tumor volume as a predictor of survival and local control in patients with brain metastases treated with gamma knife surgery. J Neurosurg. 2013; 119(5):1139-44.

28. Ernst-Stecken A, Ganslandt O, Lambrecht U, Sauer R, Grabenbauer G. Phase II trial of hypofractionated stereotactic radiotherapy for brain metastases: results and toxicity. Radiother Oncol. 2006;81(1):18-24.

29. Kirkpatrick JP, Soltys SG, Lo SS, Beal K, Shrieve DC, Brown PD. The radiosurgery fractionation quandary: single fraction or hypofractionation? Neuro-Oncol. 2017;19(suppl_2):ii38-49.

30. Pacelli R, Mansi L, Hall E, Amato J. Giaccia: Radiobiology for the radiologist, 6th edn. Eur J Nucl Med Mol Imaging. 2007;34(6):965-6.

31. Inoue HK, Sato H, Suzuki Y, Saitoh J, Noda S, Seto K, et al. Optimal hypofractionated conformal radiotherapy for large brain metastases in 
patients with high risk factors: a single-institutional prospective study. Radiat Oncol Lond Engl. 2014;9:231.

32. Giubilei C, Ingrosso G, D'Andrea M, Benassi M, Santoni R. Hypofractionated stereotactic radiotherapy in combination with whole brain radiotherapy for brain metastases. J Neurooncol. 2008;91(2):207-12.

33. Marchetti M, Milanesi I, Falcone C, De Santis M, Fumagalli L, Brait L, et al. Hypofractionated stereotactic radiotherapy for oligometastases in the brain: a single-institution experience. Neurol Sci. 2011;32(3):393-9.

34. Minniti G, Scaringi C, Paolini S, Lanzetta G, Romano A, Cicone F, et al. Single-fraction versus multifraction $(3 \times 9 \mathrm{~Gy})$ stereotactic radiosurgery for large $(>2 \mathrm{~cm}$ ) brain metastases: a comparative analysis of local control and risk of radiation-induced brain necrosis. Int J Radiat Oncol. 2016;95(4):1142-8.

35. Lehrer EJ, Peterson JL, Zaorsky NG, Brown PD, Sahgal A, Chiang VL, et al. Single versus Multifraction Stereotactic Radiosurgery for Large Brain Metastases: An International Meta-analysis of 24 Trials. Int J Radiat Oncol Biol Phys. 2019;103(3):618-30.

36. Mahajan A, Ahmed S, McAleer MF, Weinberg JS, Li J, Brown P, et al. Postoperative stereotactic radiosurgery versus observation for completely resected brain metastases: a single-Centre, randomised, controlled, phase 3 trial. Lancet Oncol. 2017;18(8):1040-8.

37. Lamba N, Cagney DN, Brigell RH, Martin AM, Besse LA, Catalano PJ, et al. Neurosurgical resection and stereotactic radiation versus stereotactic radiation alone in patients with a single or solitary brain metastasis. World Neurosurg. 2019;122:e1557-61.

38. Lesueur P, Lequesne J, Barraux V, Kao W, Geffrelot J, Grellard J-M, et al. Radiosurgery or hypofractionated stereotactic radiotherapy for brain metastases from radioresistant primaries (melanoma and renal cancer) Radiat Oncol Lond Engl. 2018;13(1):138.

39. Scorsetti M, Facoetti A, Navarria P, Bignardi M, De Santis M, Ninone SA, et al. Hypofractionated stereotactic radiotherapy and radiosurgery for the treatment of patients with radioresistant brain metastases. Anticancer Res. 2009;29(10):4259-63

40. Fokas E, Henzel M, Surber G, Kleinert G, Hamm K, Engenhart-Cabillic R. Stereotactic radiosurgery and fractionated stereotactic radiotherapy: comparison of efficacy and toxicity in 260 patients with brain metastases. J Neurooncol. 2012;109(1):91-8

\section{Publisher's Note}

Springer Nature remains neutral with regard to jurisdictional claims in published maps and institutional affiliations.

Ready to submit your research? Choose BMC and benefit from:

- fast, convenient online submission

- thorough peer review by experienced researchers in your field

- rapid publication on acceptance

- support for research data, including large and complex data types

- gold Open Access which fosters wider collaboration and increased citations

- maximum visibility for your research: over $100 \mathrm{M}$ website views per year

At $\mathrm{BMC}$, research is always in progress.

Learn more biomedcentral.com/submissions 